\title{
Nigerian Physiotherapy Clinical Students' Perception of their Learning Environment Measured by the Dundee Ready Education Environment Measure Inventory
}

\author{
Adesola C. Odole $(\mathrm{PhD})^{1,2}$, Olufemi O. Oyewole $(\mathrm{PhD})^{3} \&$ Oluwasolape T. Ogunmola (BPT) ${ }^{1}$ \\ ${ }^{1}$ Physiotherapy Department, University of Ibadan, Ibadan. Nigeria \\ ${ }^{2}$ School of Research and Postgraduate Studies, Faculty of Agriculture, Science and Technology, North West \\ University, Mafikeng Campus, South Africa \\ ${ }^{3}$ Physiotherapy Department, Olabisi Onabanjo University Teaching Hospital, Sagamu. Nigeria \\ Correspondence: Olufemi O. Oyewole, Physiotherapy Department, Olabisi Onabanjo University Teaching Hospital, \\ PMB 2001, Sagamu. Tel: 234-80-3397-0714. E-mail: oyewoleye@yahoo.co.uk
}

Received: April 4, 2014

Accepted: April 21, 2014

Online Published: April 28, 2014

doi:10.5430/ijhe.v3n2p83

URL: http://dx.doi.org/10.5430/ijhe.v3n2p83

\begin{abstract}
The identification of the learning environment and the understanding of how students learn will help teacher to facilitate learning and plan a curriculum to achieve the learning outcomes. The purpose of this study was to investigate undergraduate physiotherapy clinical students' perception of University of Ibadan's learning environment. Using the quantitative research approach, a cross-sectional survey design was used in this study with data collected through the completion of the Dundee Ready Education Environment Measure (DREEM) questionnaire by 54 consenting undergraduate physiotherapy clinical students in the University of Ibadan who have had clinical education for at least one semester. The mean 131/200 indicated that the physiotherapy clinical students' perceptions of their learning environment were "more positive than negative". Use of score descriptors for the subscale scores for the DREEM indicated that students' perception of learning was positive, and their perceptions of the teachers were that they were "moving in the right direction". Their academic self-perception was positive, as was their perception of the atmosphere. The students' social self-perception was "not too bad". Only six out of the 50 items were reported to have mean scores of less than 2.00 , this implies that the items should be examined more closely, as they indicate problem areas. This study has provided useful information on student perceptions of their learning environment by using the DREEM inventory. The overall DREEM mean score indicating that the perceptions of the clinical physiotherapy students of their learning environment were "more positive than negative".
\end{abstract}

Keywords: Learning environment, DREEM, Students' perception, Physiotherapy, Clinical education

Note: “..." = direct quotes from DREEM measure.

\section{Introduction}

Learning is described as the process whereby knowledge is created through the transformation of experience (Brown, Williams, \& Lynch, 2011). The educational environment is defined as everything that happens within the classroom, department, faculty or university (Lokuhetty, Warnakulasuriya, Perera, De Silva, \& Wijesinghe, 2010). It is also defined as the interactive network of forces (i.e. physical, social, and intellectual), conditions and external stimuli within the teaching and learning activities which challenge, surround, engulf, and play on the students' learning outcomes (Said, Rogayah, \& Hafizah, 2009). Students' perception of the educational environment is a useful basis for modifying and improving its quality and provides students with a louder voice by which they can share their experience in the school (Prayoonwong \& Nimnuan, 2010). The educational environment is not restricted to student-teacher interaction, teaching and learning activities, but also includes having good facilities and physical structures provided by the institution. The learning environment is not only a significant determinant of curriculum but is as well as salient index of the behavior of both the students and teachers (Demiroren, Palaoglu, Kemahli, Ozyurda, \& Ayhan, 2008).

A favorable educational environment, such as comfortable learning rooms, receptive clinical environment and motivated, skilled and friendly teachers, is said to increase student motivation, which in turn leads to enhanced 
commitment in learning and improved performance (Hutchinson, 2003). Motivated learners in supportive environments have high levels of self-efficacy (Lokuhetty et al, 2010). A favorable environment has a positive and important impact on students' learning, academic growth, and well-being (Arzuman, Yusoff, \& Chit, 2010). The learning environment is one of the most significant factors in determining the success of an effective curriculum (Arzuman et al, 2010). The importance of the educational environment in student learning is widely acknowledged (Lai, Nalliah, Jutti, Hla, \& Lim, 2009). The learning environment includes cultural, social, and psychological elements, in addition to the physical surroundings (Arzuman et al, 2010). The development of healthcare practitioners depends, significantly, on the attributes of the environment where they study or work (Arzuman et al, 2010).

The learning environment makes an impact on students' learning experiences and outcomes (Al Rukban, Khalil, \& Al-Zalabani, 2010). The trainer or facilitator is one of the most potent variables in the learning environment (Hutchinson, 2003). The approach used in teaching and learning activities can be teacher-centered, wherein information is provided through lecture to a large number of students, and the students entirely depend on the information gathered in their lectures (Said et al, 2009). An effective training programme is that which provides students with a variety of learning experiences and that which involves them during the real learning process (Pimparyon, Roff, Mcaleer, Poonchai, \& Pemba, 2000). Respect for the learners and their needs, encouragement of participation can all result to a positive learning experience (Hutchinson, 2003).

Review of published literature which used DREEM inventory to assess medical or health sciences students' perception of learning environment generally revealed that their perception were "more positive than negative" with the exception of two studies which reported that students perceived "plenty of problems" in their educational environment (Al-Ayed \& Sheikh, 2008; Audinet, Davy, \& Barkham, 2003). Most studies reported that students' perception of teacher (SPoT) subscale was the highest contributing domain to the overall DREEM scores (Brown et al, 2011; Lai et al, 2009; Bouhaimed, Thalib, Doi, 2009; Abraham, Ramnarayan, Vinod, \& Torke, 2008; Demiroren et al, 2008; Al-Ayed \& Sheikh, 2008; Varma, Tiyagi, \& Gupta, 2005) while seven studies reported either students' social self-perception (SSSP) or students' academic self-perception (SASP) as lowest contributing subscale to the overall DREEM score (Brown et al, 2011; Lai et al, 2009; Bouhaimed et al, 2009; Riquelme et al, 2009; Abraham et al, 2008; Miles \& Leinster,2007; Varma et al, 2005). The data from the reviewed studies suggested that the higher the SPoT, the more positive perception of educational environment by the students (Brown et al, 2011; Lai et al, 2009; Said et al, 2009; Varma et al, 2005). Students' year of study were found to influence perception of educational environment. The positive perceptions of learning environment were decreasing as the students advanced in their years of study (Brown et al, 2011; Riquelme et al, 2009; Said et al, 2009; Demiroren et al, 2008; Al-Ayed \& Sheikh, 2008; Abraham et al, 2008). Students who enrolled immediately in their course after completion of higher school yielded low score of DREEM compared with those who enroll later (Brown et al, 2011). The influence of gender on perception of learning environment was reported by four studies. Two of the studies reported that females have more positive perception of their educational environment than the males (Brown et al, 2011; Lokuhetty et al, 2010) while the others did not find significant gender difference (Abraham et al, 2008; Al-Ayed \& Sheikh, 2008).

Several studies have been conducted on the perception of the learning environment among dental, nursing and medical students in many developed and developing countries of the world (Prayoonwong \& Nimnuan, 2010; Al Rukban et al, 2010; Pimparyon et al, 2000). However, there appears to be no published information on the perception of the learning environment among physiotherapy students in Nigeria using a quantitative approach. Thus, this study was conducted to provide information on how undergraduate physiotherapy clinical students in the University of Ibadan perceive their learning environment.

\section{Methods}

Using the quantitative research approach, a cross-sectional survey design was used in this study. The Dundee Ready Education Environment Measure (DREEM) questionnaire was used to collect the data (Roff et al, 1997). Fifty four consenting undergraduate physiotherapy clinical students in the University of Ibadan who have had clinical education for at least one semester completed the DREEM questionnaire.

The choice of DREEM was based on its evidence of psychometric properties and its wide utility (Lai et al, 2009; Abraham et al, 2008; Varma et al, 2005; Roff, McAleer, \& Skinner, 2005). High internal consistency has been reported with Cronbach alpha levels of 0.92 to 0.93 (Brown et al, 2011). The DREEM questionnaire is able to evaluate both the theory and clinical practice components. The DREEM questionnaire is a fifty-item measure which is designed to assess students' perception of their learning environment. Items are in the form of statements relating to the participant's learning environment (e.g., "I am encouraged to participate in class"). Each of the 50 statements 
is scored on a 5 -point scale, where $4=$ strongly agree, $3=$ agree, $2=$ unsure, $1=$ disagree and $0=$ strongly disagree. Thus, higher scores indicate a more positive evaluation. Reverse coding is required for items $4,8,9,17,25,35,39$, 48 and 50. The 50-item DREEM has a maximum score of 200 signifying the ideal learning environment as perceived by the teacher. A score of zero is the lowest and would be a very worrying result. The total score for all scales is 200 . However, for all items, results were presented so that the higher scores represent more positive readings (a more favorable learning environment) and vice-versa.

The questionnaire consists of five domains as shown in table 1. The students' perceptions of learning (SPoL), Students' perceptions of teachers (SPoT), students' academic self-perceptions (SASP), Students' perceptions of Atmosphere (SPoA) and students' social self-perceptions (SSSP). The following is an approximate guide to interpreting the overall score: 0-50 very poor, 51-100 plenty of problems, 101-150 more positive than negative and 151-200 excellent (Roff et al, 2005).

The DREEM can also be used to pinpoint more specific strengths and weaknesses within the learning environment. Items that have a mean score $>3.5$ are real positive points, Item with a mean $<2$ should be examined more closely as they signify problem areas and Items with a mean between 2 and 3 are aspects of the learning that could be improved (Roff et al, 2005).

Table 1. Subscales of DREEM Inventory and Its Interpretation

\begin{tabular}{|c|c|c|c|}
\hline Subscale & Number of Items & Max score & Interpretation of scores \\
\hline Students' Perception of Learning & 12 & 48 & $\begin{array}{l}\text { 0-12 Very Poor } \\
\text { 13-24 Teaching is viewed negatively } \\
\text { 25-36 A more positive perception } \\
\text { 37-48 Teaching highly thought of }\end{array}$ \\
\hline Students' Perception of Teachers & 11 & 44 & $\begin{array}{l}\text { 0-11 Abysmal } \\
\text { 12-22 In need of some retraining } \\
\text { 23-33 Moving in the right direction } \\
\text { 34-44 Model teachers }\end{array}$ \\
\hline Students' Academic Self-Perception & 8 & 32 & $\begin{array}{l}\text { 0-8 Feelings of total failure } \\
\text { 9-16 Many negative aspects } \\
\text { 17-24 Feeling more on the positive side } \\
\text { 25-32 Confident }\end{array}$ \\
\hline Students' Perception of Atmosphere & 12 & 48 & $\begin{array}{l}\text { 0-12 A terrible environment } \\
\text { 13-24 There are many issues which } \\
\text { need changing } \\
\text { 25-36 A more positive atmosphere } \\
\text { 37-48 A good feeling overall }\end{array}$ \\
\hline Students' Social Self-Perception & 7 & 28 & $\begin{array}{l}\text { 0-7 Miserable } \\
\text { 8-14 Not a nice place } \\
\text { 15-21 Not too bad } \\
\text { 22-28 Very good socially }\end{array}$ \\
\hline
\end{tabular}

In order to avoid responders' bias, all the items in the five subscales were mixed up together. This questionnaire was assessed for content validity by an expert panel of four physiotherapy lecturers and two physiotherapy clinicians who are knowledgeable in questionnaire development. The questionnaire was pretested on six students (three students at each of the two levels of study) to assess for comprehensibility and non-ambiguity of words. The students reported ease of comprehension of all the items.

Prior to distribution of the questionnaire, approval was sought and obtained from the University of Ibadan/University College Hospital Research Ethics Committee. Permission was also taken from the Head of Physiotherapy Department, College of Medicine, University of Ibadan. The procedure and purpose of the study were explained to the participants and their informed consent was sought and obtained. Copies of the questionnaire were administered to all consenting students (self-administration). The completed questionnaires were collected by one of the authors. 
All the students at the two levels of study participated in the study. Prior to the study, one of the authors was approached by some of the students desiring to express their opinions regarding their learning environment.

\subsection{Data analysis}

Descriptive statistics of mean, percentages, frequency distribution was used to summarize the result. This was further illustrated using tables.

\section{Results}

The participants ( 30 males, 24 females) were aged $23.7 \pm 2.3$ with a range of $19-30$ years. Twenty-six (48.1\%) students were at the 400 level of study while twenty-eight $(51.9 \%)$ were 500 level students.

\subsection{Students' perception of their learning environment}

The overall mean score for physiotherapy clinical students' perception of their learning environment was $131.0 \pm .23 .07$ (Table2). This revealed that the physiotherapy clinical students' perceptions of their learning environment were "more positive than negative". Using score descriptors provided as an approximate guide to interpreting the subscales (Miles $\&$ Leinster, 2007). These provide a verbal description to a range of scores, which is useful in determining the level of improvement required for each subscale. Use of these descriptors for the subscale scores for the DREEM showed that students' perception of learning was "positive" (scores of 25-36), and their perceptions of the teachers was that they were "moving in the right direction" (scores of 23-33). Their academic self-perception was "positive" (scores of 17-24), as was their perception of the atmosphere (scores of 25-36). The students' social self-perception was "not too bad" (scores of 15-21). It can be noted that, in each case, University of Ibadan Physiotherapy clinical students' scores are at the middle of the scoring band. Thus, the Physiotherapy clinical students of the University of Ibadan perceived their learning environment as positive although there is room for improvement in some areas.

Table 2. Students' perception of their learning environment

\begin{tabular}{lccc}
\hline & & Years of study & \\
Items & 400 Level & 500 Level & Total \\
\hline & Mean \pm SD & Mean \pm SD & Mean \pm SD \\
\hline Students' Perception of Learning (SPoL) & $31.62 \pm 3.29$ & $31.21 \pm 4.51$ & $31.41 \pm 3.94$ \\
Students' Perception of Teachers (SPoT) & $28.54 \pm 4.67$ & $28.14 \pm 4.66$ & $28.33 \pm 4.62$ \\
Students' Academic Self-Perception (SASP) & $23.08 \pm 3.22$ & $23.29 \pm 3.77$ & $23.19 \pm 3.49$ \\
Students' Perception of Atmosphere (SPoA) & $30.19 \pm 5.28$ & $30.32 \pm 6.79$ & $30.26 \pm 6.05$ \\
Students' Social Self-Perception (SSSP) & $18.58 \pm 6.44$ & $17.04 \pm 3.00$ & $17.78 \pm 4.97$ \\
Overall score & $132.00 \pm 24.31$ & $130.77 \pm 22.75$ & $131.00 \pm 23.07$ \\
\hline
\end{tabular}

Key: 400 Level $=4^{\text {th }}$ year of study 500 Level $=5^{\text {th }}$ year of study

\subsection{Individual item analysis}

The mean scores for each individual DREEM items are shown in Table 3. These analyses allowed us to identify specific strengths and weakness within the learning environment. The mean scores of six items were less than 2.00 (items 3, 9, 14, 25, 39 and 42). Item 25 (The teaching over emphasizes factual learning) in the domain of 'the SPoL' had a mean score of $1.78 \pm 0.86$ (Table 3), indicating that this item should be examined more closely as it indicated a problem area. Item 9 (The teachers are authoritarian) and item 39 (The teachers get angry in teaching) in 'the SPoT' subscale, both have a mean score of 1.98 \pm 1.07 (Table 3). The negative-item scoring scheme indicated that students agreed with the item. The items that indicated problem areas from 'the SSSP' subscale are item 3 (there is a good support system for student who become stressed) and item 14 (I am rarely bored in this course), the mean score are $1.39 \pm 1.00$ and $1.98 \pm 1.16$ respectively (Table 3 ).

The mean scores of seven items (items $2,10,15,19,33,45$, and 46) are greater than 3.00 . Item 10 (I am confident about passing this year) had a mean score of $3.70 \pm 0.57$, which indicated that the students are positive about passing that year. Item 15 (I have good friends in this course) had a mean score of $3.11 \pm 0.72$, indicating a fairly good social life for the students. The other 37 items had a mean score between 2.00 and 3.00 (Table 3), indicating aspects of this subscale that could be improved. Item 8 (The teachers ridicule the student) and item 50 (The students irritate the teachers) from 'the SPoT' domain, both negative items, had a mean score of $2.44 \pm 0.86$ and $2.65 \pm 1.07$ respectively (Table 3 ). This indicated the students' disagreement with these items and the items should be examined more closely. Items 17 
(Cheating is a problem in this school) and 35 (I find the experience disappointing) in 'the SPoA' are both negative items (Table 3), which had a mean score of $2.11 \pm 1.62$ and $2.81 \pm 1.05$ respectively. The scores suggest that students did not fully agree with both statements.

Table 3. Individual item analysis

\begin{tabular}{|c|c|c|c|}
\hline \multirow[b]{2}{*}{ Items } & \multicolumn{3}{|c|}{ Years of study } \\
\hline & $4^{\text {th }}$ year & $5^{\text {th }}$ year & Total \\
\hline & Mean \pm SD & Mean \pm SD & Mean \pm SD \\
\hline \multicolumn{4}{|l|}{ Students' Perception of Learning (SPoL) } \\
\hline 1. I am encouraged to participate in class & $3.12 \pm 0.65$ & $2.89 \pm 0.99$ & $3.00 \pm 0.85$ \\
\hline 7. The teaching is often stimulating & $2.46 \pm 0.71$ & $2.46 \pm 0.84$ & $2.46 \pm 0.77$ \\
\hline 13. The teaching is student-centered & $2.50 \pm 1.07$ & $2.57 \pm 0.79$ & $2.537 \pm 0.93$ \\
\hline $\begin{array}{l}\text { 16. The teaching is sufficiently concerned } \\
\text { to develop my competence }\end{array}$ & $2.88 \pm 0.71$ & $2.96 \pm 0.69$ & $2.93 \pm 0.70$ \\
\hline 20. The teaching is well focused & $2.81 \pm 0.63$ & $2.75 \pm 0.84$ & $2.78 \pm 0.74$ \\
\hline $\begin{array}{l}\text { 22. The teaching helps to develop my } \\
\text { confidence }\end{array}$ & $2.96 \pm 0.72$ & $2.93 \pm 0.66$ & $2.94 \pm 0.68$ \\
\hline 24. The teaching time is put to good use & $2.27 \pm 0.87$ & $2.43 \pm 0.88$ & $2.35 \pm 0.87$ \\
\hline $\begin{array}{l}25 \text {. The teaching is over emphasised } \\
\text { compared with factual learning }\end{array}$ & $1.85 \pm 0.92$ & $1.71 \pm 0.81$ & $1.78 \pm 0.86$ \\
\hline $\begin{array}{l}\text { 38. I am clear about the learning objectives } \\
\text { of the program }\end{array}$ & $3.12 \pm 0.59$ & $2.86 \pm 0.76$ & $2.98 \pm 0.69$ \\
\hline $\begin{array}{l}\text { 44. The teaching encourages me to be an } \\
\text { active learner }\end{array}$ & $2.88 \pm 0.52$ & $2.54 \pm 1.04$ & $2.70 \pm 0.84$ \\
\hline $\begin{array}{l}\text { 47. Long term learning is emphasized over } \\
\text { short term learning }\end{array}$ & $2.46 \pm 0.90$ & $2.79 \pm 0.92$ & $2.63 \pm 0.92$ \\
\hline 48.T the teaching is too teacher centered & $2.31 \pm 0.84$ & $2.32 \pm 1.19$ & $2.31 \pm 1.02$ \\
\hline \multicolumn{4}{|l|}{ Students' Perception of Teachers (SPoT) } \\
\hline 2. The teachers are knowledgeable & $3.31 \pm 0.74$ & $3.32 \pm 0.48$ & $3.31 \pm 0.61$ \\
\hline 6. The teachers are patient with students & $2.62 \pm 0.98$ & $2.61 \pm 0.96$ & $2.61 \pm 0.96$ \\
\hline 8. The teachers ridicule the student & $2.54 \pm 0.90$ & $2.36 \pm 0.83$ & $2.44 \pm 0.86$ \\
\hline 9. The teacher are authoritarians & $2.08 \pm 0.98$ & $1.89 \pm 1.17$ & $1.98 \pm 1.07$ \\
\hline $\begin{array}{l}\text { 18. The teachers have good communication } \\
\text { skills with students }\end{array}$ & $2.96 \pm 0.72$ & $2.96 \pm 0.69$ & $2.96 \pm 0.70$ \\
\hline $\begin{array}{l}\text { 29. The teacher are good at feedback } \\
\text { to students }\end{array}$ & $2.42 \pm 0.90$ & $2.54 \pm 0.79$ & $2.48 \pm 0.84$ \\
\hline $\begin{array}{l}\text { 32. The teachers provide constructive } \\
\text { criticism here }\end{array}$ & $2.08 \pm 1.02$ & $2.39 \pm 1.03$ & $2.24 \pm 1.03$ \\
\hline 37. The teachers are approachable & $2.92 \pm 0.48$ & $2.75 \pm 0.84$ & $2.83 \pm 0.69$ \\
\hline 39. The teachers get angry in class & $2.04 \pm 1.00$ & $1.93 \pm 1.09$ & $1.98 \pm 1.04$ \\
\hline $\begin{array}{l}\text { 40. The teachers are well prepared for } \\
\text { their class }\end{array}$ & $3.00 \pm 0.57$ & $2.68 \pm 0.90$ & $2.83 \pm 0.77$ \\
\hline 50. The students irritate the teachers & $2.58 \pm 0.99$ & $2.71 \pm 1.15$ & $2.65 \pm 1.07$ \\
\hline
\end{tabular}




\section{Students' Academic Self-Perception (SASP)}

5. Learning strategies which worked for me before continue to work for me now

$2.31 \pm 0.97$

$2.46 \pm 1.14$

$2.39 \pm 1.05$

10. I am confident about my passing this year

$3.54 \pm 0.71$

$3.86 \pm 0.36$

$3.70 \pm 0.57$

21. I feel I am being well prepared for my profession

$3.04 \pm 0.66$

$2.96 \pm 0.79$

$3.00 \pm 0.73$

26. Last year's work has been a good preparation for this year's work

27. I am able to memorize all I need

31. I have learned a lot about empathy in my profession

$2.81 \pm 0.63$

$2.89 \pm 0.92$

$2.85 \pm 0.79$

$2.35 \pm 0.94$

$3.04 \pm 0.66$

$2.11 \pm 0.99$

$2.22 \pm 0.96$

41. My problem-solving skills are being well developed here

$2.81 \pm 0.63$

$3.19 \pm 0.69$

45. Much of what I have to learn seems

relevant to a career in healthcare

\section{A)}

11. The atmosphere is relaxed during the practical class

$2.35 \pm 1.17$

12. This school is well time-tabled

$2.31 \pm 1.19$

$2.32 \pm 1.36$

$2.31 \pm 1.27$

17. Cheating is a problem in this school

$1.65 \pm 1.50$

$2.54 \pm 1.64$

$2.11 \pm 1.62$

23. The atmosphere is relaxed during the lectures

$2.96 \pm 0.72$

$2.61 \pm 0.92$

$2.78 \pm 0.84$

30. There are opportunities for me to develop inter-personal skills

$2.62 \pm 0.75$

$2.79 \pm 0.79$

$2.70 \pm 0.77$

33. I feel comfortable in class socially

$3.08 \pm 0.63$

$3.00 \pm 0.72$

$3.04 \pm 0.67$

34. The atmosphere is relaxed during seminars/tutorials

$2.31 \pm 1.23$

$2.36 \pm 1.10$

$2.33 \pm 1.15$

35. I find the experience disappointing

$2.65 \pm 0.98$

$2.96 \pm 1.10$

$2.81 \pm 1.05$

$2.88 \pm 0.52$

$2.61 \pm 0.92$

$2.74 \pm 0.76$

42. The enjoyment outweighs the stress of the program

$1.73 \pm 1.25$

$1.61 \pm 1.37$

$1.67 \pm 1.30$

43. The atmosphere motivates me as a learner

$2.62 \pm 0.80$

$2.21 \pm 1.07$

$2.41 \pm 0.96$

49. I feel able to ask the questions I want $\quad 3.23 \pm 0.51$

$2.79 \pm 0.92$

$3.00 \pm 0.78$

\section{Students' Social Self-Perception (SSSP)}

3. There is a good support system for students who get stressed

$1.46 \pm 0.99$

$1.32 \pm 1.02$

$1.39 \pm 1.00$

4. I am too tired to enjoy this program

$2.77 \pm 0.86$

14. I am rarely bored on this course

$2.15 \pm 1.08$

$2.57 \pm 1.14$

$2.67 \pm 1.01$

$1.82 \pm 1.22$

$1.98 \pm 1.16$

15. I have good friends in this school

$3.15 \pm 0.54$

$3.07 \pm 0.86$

$3.11 \pm 0.72$

19. My social life is good

$3.88 \pm 5.98$

$2.86 \pm 0.89$

$3.35 \pm 4.19$

28. I seldom feel lonely and friendless

$2.15 \pm 1.16$

$1.89 \pm 1.34$

$2.02 \pm 1.25$

46. My accommodation is relevant

$3.00 \pm 0.89$

$3.50 \pm 0.51$

$3.26 \pm 0.76$

Key: 400 Level $=4^{\text {th }}$ year of study 500 Level $=5^{\text {th }}$ year of study 


\section{Discussion}

The DREEM questionnaire provided an overview of physiotherapy clinical students' perceptions of their learning environment. The overall DREEM mean score was 131.0土.23.07, indicating that the perceptions of the clinical physiotherapy students of their learning environment were "more positive than negative". In comparison, the overall DREEM scores reported for diverse medical and allied health sciences schools were 133/200 and 125/200 in Malaysia (Lai et al, 2009; Zamzuri, Azli, Roff, \& McAleer, 2004); 119/200, 114/200, and 117/200 in India (Abraham et al, 2008; Mayya \& Roff, 2004); 109/200 in Trinidad (Bassaw, Roff, McAleer, Roopnarinesingh, \& Teelucksingh, 2003); and 139/200 in the United Kingdom (Varma et al, 2005). The present study included all the students in the clinical phase of their study like most of these previous studies although some included other students at different phases with varied sample sizes. Despite the differences in settings where these studies were conducted, the mean scores fell well within the range (101-150) as ours which indicated a "more positive than negative" perception of environment. The score of 131 in the present study reflects satisfaction and might indicate a student-centred curriculum. It has been observed that students of the innovative curricula (i.e. innovative in terms of providing a student-centred approach to education) tend to show more satisfaction with their learning environments, compared to students of the traditional curricula (Said et al, 2009). Higher DREEM scores tend to signify more student-centred curricula, while those offering traditional curricula usually score less than 120 (Said et al, 2009). Two of these studies have a higher score than the present study which may reflect that these institutions are fairly innovative in terms of providing a student-centred approach to education (Brown et al, 2011). The DREEM score of 89/200 for the College of Medicine at King Saud University, Saudi Arabia is reported to be the lowest score among published studies, followed by 97/200 in the Canadian Memorial Chiropractic College study (Al-Ayed \& Sheikh, 2008; Audinet et al, 2003). It is likely that these institutions are offering conventional curricula. For instance, in one of the institutions, College of Medicine at King Saud University, Saudi Arabia, the curriculum was reported as overcrowded and teacher centred (Al-Ayed \& Sheikh, 2008). The higher scores on DREEM from this present study as compared to the scores from these two studies might be a reflection that suggests a better education environment at University of Ibadan than in these institutions. Higher DREEM scores tend to indicate more student-centred curricula that supports improved learning environment.

The scores for all the five DREEM domains reflected positive perception by the students. Moreover, these ratings also indicated that there is ample room for improvement in all five subscales of the learning environment of physiotherapy department in the University of Ibadan. It was stated that all students agreed to a more positive approach regarding their perception of learning, "moving in right direction" for perception of teachers, feeling "more on the positive side" for their academic self-perception, feeling "more on the positive side" for the perception of atmosphere. They also reported that their social self-perceptions were "not too bad". The two lowest scoring contributory subscales, perception of atmosphere $(63 \%)$ and social self-perceptions $(63.5 \%)$, were not too far different from the other three DREEM subscales or overall mean DREEM score. This might be a reflection of insufficient infrastructure or an overloaded curriculum. A similar observation was reported among final year clinical students in UK (Varma et al, 2005). Academic self-perception (72.5\%) was the highest scoring contributory domain. This was likely so because at the clinical level of their studies, it was apparent that they had achieved higher levels of cognition (application, analysis, synthesis and evaluation) in addition to lower levels of cognition (knowledge and comprehension). The individual items' mean scores offered an opportunity to enhance certain areas of the learning environment that were perceived by students. There were seven DREEM items that scored 2 or less $(3,9,14,25,28$, 39 , and 42 ). Out of the 7 items, two $(25,39)$ of them were negative (The teaching overemphasizes factual learning; the teachers get angry in class) items. Each of the items belonged to 'the SPoL' and 'the SPoT' respectively. To a large extent, the students felt that the course is overloaded with factual information and also that the "teachers get angry in class". Item 3 (There is a good support system for student who become stressed) was the lowest scored item, with a score of $1.39 \pm 1.0$. This item also had a mean score less than 2.0 in other published articles from developing nations like Nigeria (Said et al, 2009; Abraham et al, 2008). This finding indicated that the students are not aware of any support system that the department provides to facilitate learning for students when they become stressed during the course of study. As at the time of this study, support systems were centrally organized from the College and not from the department. Students often go to lecturers informally when they become stressed. Another low scored item was item 42 (The enjoyment outweighs the stress) which scored $1.67 \pm 1.30$, indicating that the program is very stressful. This explains that the curriculum could be overloaded. Another low item scored was item 14 (I am rarely bored in this course) which scored $1.98 \pm 1.16$ and this needs to be explored more to identify what causes such boredom and whether the courses can be made more engaging. Students' perceptions for Item 28 (I seldom feel lonely and friendless) were average, 2.02. This indicated that the students are sociable. 
There were 23 items that scored between 2.50 and 3.00. Students reported that their teachers have good communication skills; give clear examples and were well prepared for their teaching. They also reported that their teaching helped the students to develop professional competence. They also considered the overall atmosphere of the school as averagely comfortable and reported a good social life in item 19 (3.35 \pm 4.19$)$. Only one item, item 10 (I am confident about passing this year) of 'the SSAP' domain scored above 3.5 which is $3.70 \pm 0.57$; this indicated that the students are being taught by knowledgeable teachers (3.31 \pm 4.19) and most of what they were being taught seemed relevant to their career. Just one item in 'the SSAP' had a very positive perception. It meant that we have a lot of room for improvement and improvisation in the school learning environment.

This feedback from physiotherapy clinical students may inform a revised curriculum aimed at enhancing the quality of the learning environment in the Bachelor of Physiotherapy programme at University of Ibadan. Specifically, items that have a mean score of less than two can be addressed by the Curriculum Review Committee in the nearest future. A short-term strategic plan can be implemented in order to deliver an optimally conducive learning environment for the students.

\section{Conclusion}

This study has provided useful information on student perceptions of their learning environment by using the DREEM inventory. The overall DREEM mean score was 131/200, indicating that the perceptions of the Physiotherapy clinical students of their learning environment were "more positive than negative". Although the overall learning environment score of the University of Ibadan was observed to be "more positive than negative", there were six items out of the 50 that showed mean scores of less than 2.00 that should be examined more closely, as they indicate problem areas. Other academic institutions in Nigeria are encouraged to investigate on students' perception of their educational environment in order to enhance learning.

\section{References}

Abraham, R., Ramnarayan, K., Vinod, P., \& Torke, S. (2008). Students' perceptions of learning environment in an Indian medical school. BMC Medical Education, 8, 20-24. http://dx.doi.org/10.1186/1472-6920-8-20

Al Rukban, M.O., Khalil, M.S., \& Al-Zalabani, A. (2010). Learning environment in medical schools adopting different educational strategies. Educational Research and Reviews, 5(3), 126-129.

Al-Ayed, I. H., \& Sheikh, S. A. (2008). Assessment of educational environment at the college of Medicine of King Saud University, Riyadh. East Mediterranean Health Journal, 14(4), 953-959.

Arzuman, H., Yusoff, M.S.B., \& Chit, S.P. (2010). Big Sib Students' Perceptions of the Educational Environment at the School of Medical Sciences, University Sains Malaysia, using Dundee Ready Educational Environment Measure (DREEM) Inventory. Malaysian Journal Medical Science, 17(3), 40-47.

Audinet, K., Davy, J., \& Barkham, M. (2003). University Quality of Life and Learning (UNIQoLL): An approach to student wellbeing, satisfaction and institutional change. Journal for Further High Education, 27(4), 365-382. http://dx.doi.org/10.1080/0309877032000128073

Bassaw, B., Roff, S., McAleer, S., Roopnarinesingh, S., \& Teelucksingh, S. (2003). Students' perspectives on the educational environment. BMC Medical Teacher, 25(5), 522-526. http://dx.doi.org/10.1080/0142159031000137409

Bouhaimed, M., Thalib, L., Doi, S.A.R. (2009). Perception of the Educational Environment by Medical Students Undergoing a Curricular Transition in Kuwait. Med Princ Pract, 18,204-208. http://dx.doi.org/10.1159/000204351

Brown, T., Williams, B., \& Lynch, M. (2011). The Australian DREEM: evaluating student perceptions of academic learning environments within eight health science courses. International Journal of Medical Education, 2, 94-101. http://dx.doi.org/10.5116/ijme.4e66.1b37

Demiroren, M., Palaoglu, O., Kemahli, S., Ozyurda, F., \& Ayhan, I.H. (2008). Perceptions of Students in Different Phases of Medical Education of Educational Environment: Ankara University Faculty of Medicine. Medical Education Online, 13, 8. http://dx.doi.org/10.3885/meo.2008.Res00267

Hutchinson, H. (2003). ABC of learning and teaching. British Medical Journal, 326:810-812. http://dx.doi.org/10.1136/bmj.326.7393.810 
Lai, N.M., Nalliah, S., Jutti, R.C., Hla, Y.Y., \& Lim, V.K.E. (2009). The Educational Environment and Self perceived Clinical Competence of Senior Medical Students in a Malaysian Medical School. Education for Health, 22, 148.

Lokuhetty, M.D.S., Warnakulasuriya, S.P., Perera, R.I.R., De Silva, H.T.R., \& Wijesinghe, H.D. (2010). Students' perception of the educational environment in a Medical Faculty with an innovative curriculum in Sri Lanka. South-East Asian Journal of Medical Education, 4(1), 9-16.

Mayya, S.S. \& Roff, S. (2004). Students' Perceptions of Educational Environment: A Comparison of Academic Achievers and Under-Achievers at Kasturba Medical College, India. Education for Health, 17, 280-291. http://dx.doi.org/10.1080/13576280400002445

Miles, S., \& Leinster, S. J. (2007). Medical students' perceptions of their educational environment: expected versus actual perceptions. Medical Education, 41, 265-272. http://dx.doi.org/10.1111/j.1365-2929.2007.02686.x

Pimparyon, P., Roff, S., Mcaleer, S., Poonchai, B., \& Pemba S. (2000). Educational environment, student approaches to learning and academic achievement in a Thai nursing school. Medical Teacher, 22, 359-364. http://dx.doi.org/10.1080/014215900409456

Prayoonwong, T., \& Nimnuan, C. (2010). Dental students' perceptions of Learning Environment. South-East Asian Journal of Medical Education, 49 (1), 49-54.

Riquelme, A., Oporto, M., Oporto, J. Méndez, J.I., Viviani, P., Salech, F., Chianale, J., Moreno, R., Sánchez, I. (2009). Measuring Students' Perceptions of the Educational Climate of the New Curriculum at the Pontificia Universidad Católica de Chile: Performance of the Spanish Translation of the Dundee Ready Education Environment Measure (DREEM). Education for Health, 22, 112.

Roff, S., McAleer, S., \& Skinner, A. (2005). Development and validation of an instrument to measure the postgraduate clinical learning and teaching educational environment for hospital-based junior doctors in the UK. Medical Teacher, 27, 326-331. http://dx.doi.org/10.1080/01421590500150874

Roff, S., McAleer, S., Harden, R.M., Al-Qahtani, M., Ahmed, A.U., Deza, H., Groenen, G., \& Primparyon, P. (1997). Development and validation of the Dundee Ready Education Environment Measure (DREEM). Medical Teacher, 19, 295-299. http://dx.doi.org/10.3109/01421599709034208

Said, N.M., Rogayah, J., \& Hafizah, A. (2009). A Study of Learning Environments in the Kulliyyah (Faculty) of Nursing, International Islamic University Malaysia. Malaysian Journal of Medical Sciences, 16(4), 15-24.

Varma, R., Tiyagi, E., \& Gupta, J. K. (2005). Determining the quality of educational climate across multiple undergraduate teaching sites using the DREEM inventory. BMC Medical Education, 5, 8-11. http://dx.doi.org/10.1186/1472-6920-5-8

Zamzuri, A. T., Azli, N. A., Roff, S., \& McAleer, S. (2004). How do students at Dental Training College Malaysia perceived their educational environment. Malaysian Dental Journal, 25, 15-26. 